\title{
The regulation of Endosomal Sorting Complex Required for Transport and accessory proteins in multivesicular body sorting and enveloped viral budding - an overview
}

\author{
Ishtiaq Ahmed*1, Zain Akram¹, Hafiz M. N. Iqbal², and Alan L. Munn*1 \\ ${ }^{1}$ School of Medical Science, Menzies Health Institute Queensland, Griffith University (Gold \\ Coast campus), Parklands Drive, Southport, QLD 4222, Australia; ${ }^{2}$ Tecnologico de Monterrey, \\ School of Engineering and Sciences, Campus Monterrey, Ave. Eugenio Garza Sada 2501, \\ Monterrey, N. L., CP 64849, Mexico; *Corresponding author Emails: \\ ishtiaq.ahmed@griffithuni.edu.au (I. Ahmed); a.munn@griffith.edu.au (A.L. Munn).
}

\begin{abstract}
ESCRT (Endosomal sorting complex required for transport) machinery drives different cellular processes such as endosomal sorting, organelle biogenesis, vesicular trafficking, maintenance of plasma membrane integrity, membrane fission during cytokinesis and enveloped virus budding. The normal cycle of assembly and disassembly of some ESCRT complexes at the membrane requires the AAA-ATPase vacuolar protein sorting 4 (Vps4p). A number of ESCRT proteins are hijacked by clinically significant enveloped viruses including Ebola, and Human Immunodeficiency Virus (HIV) to enable enveloped virus budding and Vps4p provides energy for the disassembly/recycling of these ESCRT proteins. Several years ago, the failure of the terminal budding process of HIV following Vps4 protein inhibition was published; although at that time a detailed understanding of the molecular players was missing. However, later it was acknowledged that the ESCRT machinery has a role in enveloped virus budding from cells due to its role in the multivesicular body (MVB) sorting pathway. The MVB sorting pathway facilitates several cellular activities in uninfected cells, such as the down-regulation of signaling through cell surface receptors as well as the process of viral budding from infected host cells. In this review, we focus on summarising the functional organisation of ESCRT proteins at the membrane and the role of ESCRT machinery and Vps4p during MVB sorting and enveloped viral budding.
\end{abstract}

Keywords: Antiviral therapy; Budding vesicle; Class E Vps proteins; Endosome; Evagination; Endocytosis; Saccharomyces cerevisiae; Ubiquitination; Virus-like particles. 


\section{Introduction:}

Life is dependent on the coordination of the activities of various molecular machines "proteins" which provide the driving force for essential cellular processes [1]. Integral membrane proteins in endosomes that are destined for the vacuole lumen or lysosome are selectively recruited into invaginations that form on the cytoplasmic surface of the endosomal limiting membrane and are then incorporated into vesicles that are released into the endosome lumen in a process known as multivesicular body (MVB) sorting. MVB sorting is required for the degradation of some membrane proteins and the delivery of other membrane proteins that are residents of the lysosome lumen (vacuole). Multivesicular bodies (MVBs) of the endosomal system are late endosomes that possess intralumenal vesicles as well as a limiting membrane [2, 3]. MVB sorting is essential for important biological processes such as exosome-dependent intercellular signaling, endosomal sorting, organelle biogenesis, vesicular trafficking, maintenance of plasma membrane, membrane fission during cytokinesis, receptor down-regulation and antigen presentation [4-6]. Since unearthing the constituents of the MVB sorting machinery and the demonstration that MVB sorting can be exploited for virus budding, curiosity about the molecular mechanism of MVB sorting has grown [7-9]. The process of MVB sorting was initially observed and morphologically characterised in mammalian cells, although it was in Saccharomyces cerevisiae that the constituents of the MVB sorting machinery were first characterised $[2,10,11]$.

The majority of proteins that comprise the MVB sorting machinery were identified by genetic studies in yeast on the basis of their role in the vacuolar protein sorting (Vps) pathway. The class E VPS genes encodes the MVB sorting machinery component proteins. The MVB sorting proteins assemble to form discrete multimeric protein complexes, i.e. ESCRT-0, -I, -II, and III. ESCRTs, which were first defined in yeast on the basis of their role in the vacuolar protein sorting pathway $[12,13]$. ESCRT-0, -I and -II are transiently recruited to the endosomal limiting membrane when cargo membrane proteins selection is carried out. ESCRT-I and II are also important for the precise recruitment and association of ESCRT-III $[11,14,15]$. There is some disagreement in the literature regarding the role of ESCRT-II in the MVB sorting. Some groups have reported evidence that ESCRT-II complex is required for the MVB sorting in yeast and mammals, however, some disagree and are of the view that ESCRT-II is not required for MVB sorting in mammals [16-19]. ESCRT machinery also functions in the abscission (last) stage of cytokinesis and during enveloped viral budding. The harmonisation of activities (e.g., membrane remodeling) is performed by ESCRT-III and a few other proteins found on the 
endosomal limiting membrane, the de-ubiquitinating enzyme Doa4p along and Bro1p [20-22]. The AAA-ATPase Vps4p/SKD1 plays an essential role in the recycling of the ESCRT-III components from the endosomal membrane into the cytoplasm. This recycling is required for the MVB sorting to be sustainable [23, 24].

ESCRT-III is involved in the MVB sorting process. Initially, subunits of ESCRT-III are recruited and activated. The assembly of ESCRT-III subunits on the membrane plays an important role in membrane remodeling (i.e. mediates membrane fission). During MVB sorting, Vps4p mediates the disassembly of the ESCRT-III sub-complexes (e.g., Vps24pVps $2 p$ ) from the limiting membrane of the endosome to recycle ESCRT components into the cytoplasm for the next round of MVB sorting; however, the molecular mechanism that coordinates ATP hydrolysis with the budding of intralumenal vesicles has yet to be defined [25]. Vta1/SBP/Lip5 protein is a positive regulator of Vps4p ATPase activity and acts together with the ESCRT-III subunits (detailed explanation of ESCRT-III disassembly/recycling is given in Section 4) [26-29].

Here we focus on illustrating the role of ESCRT proteins and addressing unresolved questions surrounding the molecular mechanisms by which they function. Moreover, we review the significance of the ESCRT proteins and their role in intralumenal vesicle budding and the important role of the ubiquitin cycle in marking cargo proteins for inclusion in intralumenal vesicles. We also explain the role of ESCRT proteins in HIV infection, the current inhibitors of HIV available in the market and the potential for inhibition of MVB sorting as an anti-HIV therapy.

\section{Multivesicular body sorting}

The components of the machinery responsible for MVB sorting have been identified in a wide range of eukaryotes. It now seems likely that ESCRT proteins will be involved in MVB sorting in all eukaryotes. It was first discovered in yeast that a subset of vacuolar protein sorting gene (i.e. the class E VPS genes are required for MVB sorting) [13]. In the Twentieth Century, Emr and Stevens and coworkers identified various genes in S. cerevisiae which when mutated conferred Vps defects [17, 30-32]. These VPS genes were initially classified into three different classes: A, B, and C, according to the vacuolar morphology that is displayed by yeast deficient in each gene. Later, three additional classes were introduced known as classes D, E, and F. Class "E" vps mutants accumulate a unique endosome-derived pre-vacuolar compartment referred to as the "class E compartment" [33-35]. The requirement of the class E VPS gene for 
MVB sorting was verified by following the trafficking of the vacuolar hydrolase carboxypeptidase S (CPS) which is a transmembrane protein that is subject to MVB sorting into the intralumenal vesicles of the vacuole. In class E Vps mutants CPS accumulates in the class E compartment and the CPS that does reach the vacuole is in the limiting membrane of the vacuole and not in the lumen of the vacuole [13,36, 37].

Studies of the proteins encoded by class E VPS gene revealed that they associate into distinct protein complexes and that these are directly required to facilitate MVB sorting [38-40]. All these complexes are mandatory for the development of the MVB and have been recruited sequentially from the cytoplasm to the limiting membrane of the late endosome (Fig. 1). ESCRT-III is dissimilar to the other ESCRT complexes (ESCRT-0, -I, -II) in terms of its stability and cytoplasmic activities [41-43]. However, an integrated view of the threedimensional (3D) structure of the ESCRT-III complex is not yet well established. The four core subunit proteins of ESCRT-III complex are: Vps20p, Snf7p, Vps24p, Vps2p [39, 42, 44] (Table 1) and each has one or more corresponding mammalian ortholog(s) which is/are designated as a Charged MVB Proteins (CHMP-6, -4, -3, -2 isoforms designated by letters (a, b, c), respectively) [25, 44,45$]$.

The process of MVB sorting is well-conserved between yeast and mammalian cells [2]. However, the number of components of the MVB sorting machinery is greater in mammalian cells due to the multiplicity of isoforms [46, 47]. Cargo membrane protein identification and recruitment occur via modification of the cytoplasmic domains of the cargo membrane proteins with ubiquitin [11, 48-50]. Ubiquitin is a protein with 76 amino acids and serves as a sorting signal for ESCRT dependent MVB sorting when it is covalently conjugated to cargo membrane proteins. Ubiquitin sorting signal on signaling receptors can be recognised by two cellular sorting mechanisms [(i) modification of protein transport machinery (ii) attachment to transmembrane proteins to control their movement between different compartments] to induce down-regulation of signaling activity and receptor degradation in the lysosome [44, 51, 52]. The cargo membrane proteins function in the formation of small membrane containers called vesicles as the cargo molecules (including proteins which possess large size) are packaged into vesicles. These vesicles are then delivered to other compartments within the cell e.g. lysosome to transfer their content or exported from the cell as exosomes (exosomes vesicles). MVB sorting of these cargo membrane proteins can be monitored through the serial recruitment of components of the MVB sorting machinery. The diverse components of the endosomal membrane are the first to arrive that represent the cargo proteins to be sorted. Structural 
information for numerous endosomal membrane components that go for MVB sorting has been reviewed by $[12,53]$. One critical step during the MVB sorting is the disassembly of the sorting machinery. This disassembly permits recycling of the MVB sorting machinery and thereby new rounds of MVB sorting and intralumenal vesicle budding. However, the molecular mechanisms responsible for the cycling of MVB sorting machinery components on and off the cytoplasmic surface of endosomal membrane is not well-studied [13, 54].

MVBs are formed coincident with the invagination of the endosomal limiting membrane and the budding of vesicles which contain transmembrane protein cargoes into the lumen [55]. The fusion of an MVB with a lysosome/vacuole is characteristic of the process by which some endocytosed transmembrane proteins are degraded in eukaryotic cells [56-58]. There are differences in this pathway (Vps) between mammals and yeast and we focus to describe the pathway in yeast. It is also characteristic of the process by which vacuolar resistant proteins (e.g. proteases) are delivered to the vacuole. Some others are recycled to plasma membrane, others are stable resident of the vacuole/lysosomes. When surface evaginations appear on the limiting membrane of the late endosome and then undergo fission this creates intralumenal MVB vesicles of $25 \mathrm{~nm}$ (in yeast) and $50 \mathrm{~nm}$ (in mammals) diameter [59]. Tens or even hundreds of these vesicles are found in a typical mature MVB which then goes on to fuse with the lysosome/vacuole. Upon delivery to the lysosome, the intralumenal vesicles are subject to hydrolytic degradation [60-62].

The pool of some receptors (recycling receptors) at the cell surface is supplemented by the recycling to the cell surface of receptors endocytosed from early endosomes [1, 63-66]. The budding, as well as the release (via membrane fission) into the endosome lumen of small membrane vesicles carrying membrane proteins cargo undergoing MVB sorting (internalized receptors), are mediated the by ESCRT-III complex and Vps4p. Topologically, the exvagination and budding of intralumenal vesicles containing cytosol from the endosomal limiting membrane is a process analogous to the budding of retroviruses as well as the vesicles that fuse to promote cytokinesis $[9,11,67,68]$. This is because in all three processes the membranes bud away from the cytoplasm. Also, the MVB sorting machinery has been shown to play a role in each of these processes [11, 12, 69]. As well as MVB sorting, ESCRT-III and Vps4p are important for ongoing membrane traffic through the MVB/late endosome and therefore the delivery of endocytosed cell surface proteins as well as newly-synthesised hydrolases to the lysosome/vacuole (many other proteins are also required for this) [51, 70-72]. 


\section{Regulation of ESCRT machinery in Multivesicular body sorting}

Biochemical and genetic investigations of these remaining (three) uncharacterised proteins encoded by class E VPS genes led to the assignment of these proteins (based on their proteinprotein interactions) to either ESCRT-II or ESCRT-III. It is now clear that the ESCRT-II complex is a stable, soluble, and heterooligomeric complex of $155 \mathrm{kDa}$ comprising Vps22p/25p/36p. The structural components of the ESCRT-III complex, on the other hand, are monomeric in the cytosol and associate into a complex only when they are recruited to membranes $[15,39,40,43,73]$.

The newly identified two ESCRT-II and ESCRT-III complexes were found involve in MVB sorting. ESCRT-II and -III act in concert with ESCRT-I to promote MVB sorting [39, 40]. The available data has been interpreted in terms of a successive activation and assembly of the three ESCRT complexes (Fig. 1). However, whether there is any strict requirement for ESCRT-I in the assembly of ESCRT-III in vivo is made unclear by the high basal levels of ESCRT-II activity [40]. Initially, it seemed unclear how ESCRT-I would stimulate ESCRT-II since protein interaction between ESCRT complexes I and II had not been identified. However, later studies identified protein interactions between human ESCRT-I and ESCRT-II subunits [15, $40,43,74,75]$. The binding of the ESCRT-I complex to ubiquitinated cargo proteins is the trigger to activate the ESCRT-II complex. The activated ESCRT-II complex then interacts with the ESCRT-III complex via direct physical association with the Vps20p/Snf7p sub-complex. Once ESCRT-II is activated, it stimulates the assembly of multiple copies of ESCRT-III onto the membrane to create a large oligomer [11, 44]. Based on their functions, the ESCRT-III complex components can be divided into two distinct groups: those that form a sub-complex comprising Snf7p and Vps20p and those that form a sub-complex comprising Vps2p and Vps24p). In a concluding step, the ESCRT-III Vps2p/Vps24p sub-complex acts together with the AAA-ATPase Vps4p to catalyse the disassembly of the entire ESCRT-III machinery from the membrane $[76,77]$.

Prior to disassembly of the ESCRT-III complexes and fission of the membrane to release an intralumenal vesicle, the ubiquitin must be recycled from ubiquitinated cargo proteins [11, 21, $41,44,78]$. The recycling of ubiquitin from the evaginating membrane into the cytoplasm is carried out by the deubiquitinating enzyme Doa4p. This recycling of ubiquitin prevents the degradation of ubiquitin in the vacuole. Doa4p is not required for vesicle assembly, however, it assists ESCRT-II with the recruitment of the ESCRT-III complex [21, 50]. The well-studied components of ESCRT-0,-I,-II and -III and the AAA-ATPase Vps4p together comprise 13 of 
the 16 proteins encoded by the class E VPS genes, suggesting that more ESCRT complexes remain to be discovered or that some components of known ESCRT complexes are yet to be assigned to a complex $[42,79,80]$. These proteins may have redundant or regulatory roles since mutants defective in these class E Vps proteins have extremely mild phenotypes [40, 81].

\subsection{The role of Vacuolar protein sorting 27 in MVB sorting}

The class E Vps protein Vps27p belongs to the ESCRT-0 complex and plays an important role in MVB sorting. In the process by which ubiquitinated cargo proteins are recruited and clustered, Vps27p may work upstream of the ESCRT-I complex [69, 74, 82, 83]. In support of this, ubiquitin binds directly to Vps27p and deletion of the Vps27p ubiquitin-interacting motif blocks the MVB sorting of a ubiquitinated cargo protein and, significantly, without having any apparent effect on vesicle budding and release into the MVB lumen [13, 21, 66, 84, 85]. This MVB sorting defect in Vps27p-deficient cells, coupled with the direct binding of Vps27p to ubiquitin has led to the proposal that Vps27p could be a major sorting receptor for ubiquitinated cargo proteins. This role has been attributed to the ESCRT-I complex, however, the direct association of the ESCRT-I complex with ubiquitinated cargo proteins has not yet been established $[17,83,86]$. It is possible that Vps27p and the ESCRT-I complex act in concert to identify the ubiquitinated cargo proteins and then one or the other of them could recruit the other components of the cellular machinery that sorts ubiquitinated cargo proteins into intralumenal vesicles [21]. Remarkably, Hrs (the mammalian ortholog of yeast Vps27p) is itself mono-ubiquitinated and can act as an adaptor to link the ESCRT-I complex to the ubiquitinated cargo protein $[6,66,83,87]$.

\subsection{Tumor susceptibility gene 101 and Multivesicular body sorting}

Tumor susceptibility gene (Tsg101) (the mammalian homologue of the yeast Vps23p) plays an important role in MVB sorting. Tsg101 is so-named because it was discovered in a mammalian cell-based screen for potential tumor suppressor genes [86, 88, 89]. Several studies have reported that Tsg101 plays a significant role in the mammalian equivalent of the yeast Vps pathway and MVB sorting $[88,90]$. There are two alternative points of entry into the membrane trafficking pathway to the lysosome/vacuole: one is via vesicular traffic from the Golgi (e.g. in the case of newly-synthesised lysosomal resident proteins) and the other is via internalisation from the plasma membrane by endocytosis (e.g. in the case of downregulation of cell surface receptors) [65, 88, 91]. Upon deletion of the gene that encodes yeast Tsg101 protein orthologue, Vps23p: (1) a Class E Vps phenotype is observed (2) membrane traffic to the 
vacuole is blocked at the endosome and (3) down-regulation of cell surface receptors is slightly inhibited $[65,89,92]$.

Investigations have shown that Vps28p is engaged by Vps23p and also Vps37p to form the "ESCRT-I" complex (350 kDa) which in turn function to identify the cargo to be incorporated into the MVB intralumenal vesicles [53, 93]. In vivo, targeting to the MVB intralumenal vesicles requires cargo ubiquitination. This study, as well as previous studies, has shown that ubiquitin conjugation and the yeast MVB sorting pathway act in concert to target cargo membrane proteins to the lysosome lumen including both proteins destined for hydrolytic destruction as well as newly-synthesised lysosomal/vacuolar resident proteins $[8,52,86,91]$. Although the mammalian MVB sorting pathway is not well-characterised, it is thought that analogous roles are performed by the yeast Vps23p and mammalian Tsg101 protein [83, 89, 93]. Evidence that TSG101 and the mammalian ESCRT-I complex plays a role in MVB sorting comes from the observation that a fibroblast cell line homozygous for a mutation in the Tsg101 gene exhibits in defects in MVB sorting of the epidermal growth factor receptor (EGFR) and hence altered EGFR trafficking $[8,11,94]$. Only the mammalian Tsg101 protein can bind the motif Pro-Thr-Ala-Pro (PTAP or analogous cargo membrane proteins), and this might represent a mechanistic difference between the human and yeast proteins. The PTAP motif is a conserved late domain motif (located in the p6 region of Gag protein) which plays an important role in the recruitment of ESCRT complexes to the site of enveloped virus budding $[47,95,96]$.

Remarkably, retroviruses, such as the human immunodeficiency virus (HIV) and other enveloped viruses, such as Ebola, recruit Tsg101 to the plasma membrane where it facilitates the recruitment of the cellular MVB sorting machinery and promotes the budding of the viruses. The number of components of the cellular MVB sorting machinery that are recruited to the plasma membrane and contribute to viral release has not yet been determined [97-99].

\section{Recruitment and assembly of subunits of the ESCRT-III complex}

ESCRT-III monomers (described previously) are not only localised on the endosomal membrane but also exist in the cytoplasm in an auto-inhibited "closed" state. The precise mechanism of auto-inhibition has not yet been determined in detail. However, it seems to involve intra-molecular interactions between the negatively-charged $\mathrm{C}$ - and positivelycharged N-termini of some and possibly all ESCRT-III subunits [59, 100, 101]. Along with other associated factors, ESCRT-II actively participates in the recruitment of ESCRT-III. 
ESCRT-II subunit Vps25p binds to the ESCRT-III subunit Vps20p. This activates ESCRT-III and triggers the recruitment of ESCRT-III subunits from the cytoplasm onto the endosomal membrane and the assembly of the ESCRT-III subunits into an ESCRT-III complex [101, 102]. This process occurs in several stages, Vps20p is recruited first to the endosomal membrane. Snf7p is then recruited by Vps20p and the Snf7p homo-oligomerises. The recruitment of Vps $24 p$ results in the capping of Snf7p polymers. When mixed at a stoichiometric ratio of 10:1 with Snf7p in vitro Vps24p can reduce Snf7p homo-oligomerisation. The act of recruitment of Vps24p (3-5 per 1 Vps20p and 10 Snf7p) terminates Snf7p homo-oligomerisation and initiates disassembly in vitro $[42,43,103]$. The ESCRT-III adaptor protein (Bro1p/Alix) is recruited to the endosome by Snf7p (Snf7p forms filaments and stabilises those filaments comprising the other ESCRT-III subunits that forms on the surface of the endosome) $[22,38]$. Vps $2 p$ is then recruited to the endosome by Vps24p thus completing the assembly of the ESCRT-III complex.

The order of recruitment of ESCRT-III subunits has, therefore, been confirmed. However, investigations to date have not yet revealed the precise stoichiometry of the accessory proteins relative to the core ESCRT-III subunits. There are also a number of 'accessory' ESCRT-III subunits which mediate the ESCRT-III-complex-Vps4p interaction [26, 28, 70, 104, 105]. These "accessory" ESCRT-III subunits which play a role in regulation of the interactions between ESCRT-III and other proteins include Vps60p, Ist1p, Did2p and Vta1p [40, 69].

In three ways ESCRT-III accessory factors seem to modulate Vps4p functions, and this is via 1) Vps4p interactions with itself (i.e., homo-oligomerisation), 2) Vps4p interactions with the subunits of ESCRT-III, and 3) Vps4p-mediated ATP hydrolysis. Vta1p stimulates the Vps4p ATPase activity, and Vps4p and Vta1p have been proposed to form an oligomeric supercomplex in which there is a $2: 1 \mathrm{Vps} 4 \mathrm{p}: \mathrm{Vta} 1 \mathrm{p}$ ratio $[26,28,70,104-107]$. However, some studies showed that Vta1p does not stimulate the ATPase activity of Vps4p as strongly as other Vps4p-binding proteins e.g. Vps20p [29]. The Vps4p-Vta1p super complex seems to be stabilised by the addition of a flexible Vtalp “cap". The ESCRT-III subunits (in particular Vps60p) engage in direct physical interaction with a number of proteins (other ESCRT-III subunits e.g. Vps2p, Vps20p, directly bind to Vps4p) including Vta1p. The interactions are mediated by the N-termini of Vtalp binding to the MIT-interacting motifs (MIMs) MIM1 (present in Vps2p, Vps24p, Did2p) and MIM2 (Vps20p, Snf7p, Vps60p) domains. This complex then binds to the MIT domain of Vps4p. Thus, Vtalp may function as an adaptor to bridge ESCRT-III subunits (like Vps60p) to Vps4p. However, many ESCRT-III subunits also interact directly with the MIT domain of $\operatorname{Vps} 4 p[26,71,79,104,107,108]$. 
In yeast, the efficiency of ESCRT-III-dependent cargo membrane sorting is substantially reduced by the loss of Brolp/Alix protein [109]. Association of the ESCRT-III subunit Snf7p oligomer and Brolp is required for the recruitment of the deubiquitinating enzyme Doa4p [20, $66,109]$. Once the assembly of the Vps4p-Vtalp complex is complete, the ESCRT-III complex (i.e. in vitro the ESCRT-III complex can work without Vps4p-Vta1p complex) triggers budding and fission of the evaginating membrane to release an intralumenal vesicle and the assembly of ESCRT-III provides the required energy [70, 79].

\section{Role of Vacuolar protein sorting 4 in Recycling of ESCRTs}

Vps4p is a multimeric mechanoenzyme that engages ESCRT-III subunits via interaction of its N-terminal MIT domain with MIM domains (found at the C-terminal region of each ESCRTIII subunit) [70, 79, 105, 110-112]. In vitro, Vps4p exists in either one of two forms: an ADPbound dimer or a nucleotide-free monomer. However, the Vps4p monomers and dimers first associate to form a stable dodecamer comprising one or two hexameric rings (some disagreements in literature) and then, upon recruitment of Vta1p, a fully assembled super complex [70, 79, 85, 106, 112]. Association of Vps4p into oligomer stimulates ATP hydrolysis by Vps4p and the association of Vps4p with ESCRT-III subunits. This in turn results in the release of ESCRT-III subunits from the membrane and their recycling to the soluble cytoplasmic pool. In yeast that express a mutated form of Vps4p (Vps4p-E233Q) that is defective in ATP hydrolysis hyper-oligomeric ESCRT-III subunits accumulate on the limiting membrane of the endosome resulting in formation of an aberrant dysfunctional late endosome known as characteristics of class E Vps mutants [15, 28, 79, 104, 105, 113].

It has been proposed that the capturing and "threading" of protein substrates through a narrow central pore in the ring-shaped AAA oligomer causes unfolding of ESCRT-III proteins and their dissociation of ESCRT-III complex. The threading through the central pore of the Vps4pVtalp complex is an ATP-dependent process [79, 104, 105, 107]. Mutational subsitution of key charged residues located in the active site of Vtalp such as arginine and lysine with aspartate and alanine, respectively, decreases the binding affinity to Vps4p hexamer, however, the binding affinity increases when a key glutamate is subsituted with alanine [105]. Once ESCRT-III complexes have been disassembled in this way, the individual subunits must subsequently be refolded. However, our understanding of the process by which ESCRT-III subunits are refolded after their dissociation remains limited [72, 114]. Evidence may come from considering the case of other AAA-ATPases and their protein substrates [79]. The Snf7p and Vps20p MIM domains (MIM2) seem to bind to a distinct site within the Vps4p MIT 
domain compared to the Vps24p and Vps2p MIM domains (MIM1) [43, 44]. The low-affinity binding between the Vps4p MIT domain and the MIM domains of the various ESCRT-III subunits suggests that simultaneous interaction with several ESCRT-III subunits are required for stable engagement of the ESCRT-III complex with Vps4p [114-117].

Several ESCRT-III subunits may act in concert to modulate the ATPase activity of the Vps4p $[8,29]$. As discussed above, Vtalp forms a complex with Vps4p. The number of domains in the Vta1p and Vps4p subunits of this complex yields a total of 24 MIT domains for the Vps4pVtalp complex. This is a sufficient number of MIT domains to allow multiple ESCRT-III complexes to interact simultaneously with the Vps4p-Vta1p complex $[115,118,119]$. The Vps4p-Vta1p oligomer may serve as an endosomal anchor for ESCRT-III. The evidence in support of this possibility is the observation that a mutant form of $\mathrm{Vps} 4 \mathrm{p}$ that is deficient in its MIT domain is still efficiently localised to endosomes like wild-type Vps4p but results in redistribution of the ESCRT-III complex (detected using Did2p-GFP) from the endosome to the cytoplasm [51, 120-123]. However, published results illustrate that Vps4p lacking its MIT domain cannot localise to endosome [29, 113]. In Vps4A mutants ESCRT complexes accumulate on the endosome limiting membrane. In in vitro assays ESCRT-III can bud intralumenal vesicles from membranes in the absence of Vps4p [108]. Table 1 shows a comparison of the yeast and human ESCRT proteins from the perspectives of their membrane interactions, their interactions with ubiquitinated cargo, and their interactions with one another.

\section{Virus Budding and Multivesicular body sorting}

Various enveloped viruses have exploited the MVB sorting pathway as a mechanism to facilitate the budding of their virus particles $[15,42]$. These enveloped viruses possess surface proteins with peptide motifs (e.g. PTAP, PPXY) that resemble those in ESCRT proteins and that have roles in ESCRT protein recruitment. The viruses utilise these peptide motifs to recruit specific ESCRT proteins (Fig. 2) [124-126].

In the context of virus budding, recruitment of the ESCRT complexes to the plasma membrane may be a key step in the process of viral release which may occur by a process analogous to MVB sorting. Currently, key events in MVB sorting have been described, e.g. how ubiquitinated cargo membrane proteins are recruited, how ESCRT complexes are assembled, and finally how membranes evaginate and undergo a fission event to generate intralumenal vesicles. However, the process of MVB sorting is relatively different from the other (more extensively studied) vesicle transport processes. However, further investigations will provide 
the details of the various molecular mechanisms that underly the various events of MVB sorting, such as those involved in recognition of the ubiquitin signal, recruitment and assembly of ESCRT complexes, deubiquitination of cargo proteins and intralumenal vesicle (or enveloped virus) evagination and fission/release.

\subsection{Assembly of viral particles during Human Immunodeficiency Virus infection}

Studies of the mechanism of HIV budding and the 3D structure studies of the cellular machinery responsible have led to important advances in the understanding of HIV in the past 30 years [127-129]. The retroviral structural proteins: capsid protein (CA), matrix protein (MA), Nucleo-Capsid protein (NC), spacer peptide 1 (SP1), spacer peptide 2 (SP2) and p6 are all synthesised as parts of the same Gag precursor polyprotein [130-133]. However, Gag is used for the assembly of virus-like particles (VLPs) (explained in next section) at the plasma membrane and budding of VLPs in the absence of other viral components. Of the proteins within the Gag polyprotein, matrix protein (MA) has been the main focus of research into HIV viral infection (Fig. 3) [128, 134, 135]. Myristic acid is attached to the N-terminal matrix domain of Gag and a group of conserved amino acid residues within the MA domain function in concert to support Gag assembly and membrane anchoring [136, 137]. The myristic acid facilitates the interaction between Gag and the plasma membrane as well as other intracellular membranes via a myristoyl switch process (which is known to be a mechanism for regulation of Gag membrane binding) [129, 130, 138]. Phosphatidylinositol 4,5 bisphosphate, a phospholipid present in the inner leaflet of the plasma membrane and that also works together with myristic acid in the membrane can trigger the switch process [134, 139, 140].

Retroviral budding requires several domains within the Gag polyprotein and also cellular ESCRT proteins. The budding process is coordinated by an association between specific Prorich motifs identified as late (L) domains and ESCRT proteins as well as other factors that are required to recruit the budding machinery, initiate viral budding and mediate the membrane fission event that releases the budded virus from the plasma membrane [9, 68]. Thus, host factors in particular ESCRT proteins play important roles in the budding of enveloped virus particles.

\subsection{The issue of HIV hypermutation and the development of drug resistance}

A feature of the HIV genome is that it undergoes mutation of a higher incidence than most other genomes, i.e. it exhibits hypermutation. When these mutations change the structure of an HIV protein targeted by drugs that HIV protein may further no longer be effectively inhibited by the drug. Because proteins encoded by the host genome exhibit a simultaneously lower rate 
of mutation. [141, 142]. There may be advantage if viral infection can be controlled by the inhibition of a host factor rather than a protein encoded by the virus. Moreover, if the host factor is used by numerous different viruses then targeting it with drugs may be protective against multiple viruses.

To facilitate the development of improved antiviral drugs, several steps of the HIV-1 lifecycle need to be understood in more detail, including virus replication, viral particle assembly, and release. With the aim of developing chemical inhibitors of HIV-1 budding, the 3D structure of a complex comprising the p6 $\mathrm{P}(\mathrm{T} / \mathrm{S}) \mathrm{AP}$ late domain and the Tsg101 N-terminal UEV domain has been determined (Fig. 3) [141, 143]. All steps in the HIV-1 life cycle are potential targets for antiviral intervention [144]. All the inhibitors and drugs shown in Fig. 4 are approved by the FDA and are used to treat HIV-1 [142]. These drugs inhibit or block different steps of the HIV life cycle.

\section{Role of Virus-like particles in the development of antiviral therapeutics}

Virus-like particles (VLPs) are host-derived secreted membrane vesicles that are induced by the high-level expression of recombinant viral surface glycoproteins or viral matrix proteins in host cells. VLPs have been acknowledged to be attractive tools for the development of unique vaccines $[145,146]$. VLP production has been used as an experimental model to investigate the budding process of certain enveloped viruses [147-150]. Numerous enveloped RNA viruses have matrix proteins which, when expressed in uninfected host cells at high levels, induce the production of VLPs. Such viruses include the retroviruses, rhabdoviruses, filoviruses, paramyxoviruses, orthomyxoviruses and arenaviruses [145, 151-153]. Experimental evidence supports the view that the membrane budding process and the consequent release of VLPs are often promoted through a complex interaction between the viral envelope protein and the ESCRT complexes [141, 154-157]. The ESCRT complexes assemble on the endosomal membrane and trigger the formation and budding of vesicles into the lumen of MVBs. Recycling of the ESCRT complexes is carried out by the action of Vps4. Expression of dominant-negative (DN) Vps4 mutant proteins that lack the ability to either bind or hydrolyse ATP blocks the recycling of ESCRT complexes from the membrane to the cytoplasm required for sustained vesicle budding $[110,113,158,159]$.

The available data revealed that a virus protein serves to recruit the host MVB sorting machinery. For example, in the case of Marburg virus, the matrix protein Vp40 recruits the MVB sorting machinery for viral budding $[151,160]$. The Vp40 matrix protein alone can drive 
this budding process, resulting in the release of VLPs into the culture medium, when Vp40 is expressed in cultured cells (e.g. HEK293 cells). This study also identified two distinct types of VLPs: one with a vesicular and one with a filamentous morphology. Although the filamentous VLPs have Vp40 as their only protein, a substantial number of cellular host proteins are present in the vesicular VLPs. Mutation of the late domain motif in Vp40 or expression of the DN mutant form of Vps4 results in a reduction of the filamentous VLPs released quantity [151, 161, 162]. These treatments/experimental conditions inhibit both the discharge of filamentous VLPs and also MVB sorting. In contrast, the discharge of vesicular VLPs was not significantly inhibited by expression of the DN mutant form of Vps4 [151]. The expression of DN the mutation of $\mathrm{Vps} 4$ resulted in a moderate inhibition of the budding of Marburg virus particles (of a magnitude similar to that of the inhibition of VLP budding). Assaying the release of VLPs from VP40-expressing cells has been an important tool that was used to explore the budding of Marburg virus particles [161]. It is significant that both the vesicular VLPs and the isolated filamentous VLPs both are involved in the mechanism of enveloped virus budding [151, 160, $162]$.

\section{Conclusion}

In closing, significant advances have been made in elucidating the molecular mechanisms by which the ESCRT complexes and Vps4p support both MVB sorting of cargo proteins and enveloped virus budding. Although the functions of these proteins may appear complicated, they can be thought of as comprising two key aspects: cargo protein engagement and alteration of membrane topology. Further experimental studies of ESCRTs and the AAA-ATPase Vps4p will yield exciting new insights into their function.

The structural biology of HIV-1 has been studied extensively. There are now either limited or complete 3D structures available for all fifteen of its protein components. In some cases, the structures are known for the free protein as well as either substrate-bound (for enzymes) or host-factor-bound complexes. Structural biology is having a substantial effect on HIV/AIDS research by providing high-resolution 3D structures of target protein-drug as well as viral-host protein complexes. Despite these advances, only a few associations of HIV-1 proteins and host proteins which trigger key steps in the life cycle of the HIV-1 virus are known - for instance the associations that introduce the pro-viral complexes into the nucleus and the role of accessory proteins in the formation of the Gag protein complexes. 
In this context, numerous systematic and also structural studies of ESCRT-III and Vps proteins are still in progress to explore the potential of these proteins as host-specific targets for the development of anti-HIV drugs. In conclusion, against targeting host proteins such as Vps4p and ESCRT-III has the potential to solve the HIV problem and after protection emerging viruses. However, future research is required to fully explore the potential of this novel approach to eliminate HIV as a major public health issue and protect against emerging viruses.

\section{Acknowledgments}

We acknowledge Griffith University Postgraduate Research Scholarship and Griffith University International Postgraduate Research Scholarship. Research grant funding from the Medical Advances Without Animals (MAWA) Trust is gratefully acknowledged.

\section{References}

[1] R. Erdmann, AAA ATPases: Structure and function, Biochimica et Biophysica Acta (BBA)-Molecular Cell Research 1823(1) (2012) 1.

[2] S. Feyder, J.-O. De Craene, S. Bär, D.L. Bertazzi, S. Friant, Membrane trafficking in the yeast Saccharomyces cerevisiae model, International journal of molecular sciences 16(1) (2015) 1509-1525.

[3] T. Falguières, P.-P. Luyet, J. Gruenberg, Molecular assemblies and membrane domains in multivesicular endosome dynamics, Experimental cell research 315(9) (2009) 1567-1573.

[4] M. Yáñez-Mó, P.R.-M. Siljander, Z. Andreu, A. Bedina Zavec, F.E. Borràs, E.I. Buzas, K. Buzas, E. Casal, F. Cappello, J. Carvalho, Biological properties of extracellular vesicles and their physiological functions, Journal of extracellular vesicles 4(1) (2015) 27066.

[5] M. Colombo, G. Raposo, C. Théry, Biogenesis, secretion, and intercellular interactions of exosomes and other extracellular vesicles, Annual review of cell and developmental biology 30 (2014) 255-289.

[6] L. Hyka, Exosomes, their biogenesis, composition and role. Bachelor's thesis, Faculty of Sciences, Charles University (2017). http://hdl.handle.net/20.500.11956/87531.

[7] P.D. Bieniasz, Late budding domains and host proteins in enveloped virus release, Virology 344(1) (2006) 55-63.

[8] E.J. Scourfield, J. Martin-Serrano, Growing functions of the ESCRT machinery in cell biology and viral replication, Biochemical Society Transactions 45(3) (2017) 613-634.

[9] E. Morita, W.I. Sundquist, Retrovirus budding, Annu. Rev. Cell Dev. Biol. 20 (2004) 395425 .

[10] E.M. Wenzel, S.W. Schultz, K.O. Schink, N.M. Pedersen, V. Nähse, A. Carlson, A. Brech, H. Stenmark, C. Raiborg, Concerted ESCRT and clathrin recruitment waves define the timing and morphology of intraluminal vesicle formation, Nature communications 9(1) (2018) 2932.

[11] J. Schöneberg, I.-H. Lee, J.H. Iwasa, J.H. Hurley, Reverse-topology membrane scission by the ESCRT proteins, Nature reviews Molecular cell biology 18(1) (2017) 5.

[12] J.H. Hurley, S.D. Emr, The ESCRT complexes: structure and mechanism of a membranetrafficking network, Annual review of biophysics and biomolecular structure 35 (2006) 277.

[13] R.C. Piper, D.J. Katzmann, Biogenesis and function of multivesicular bodies, Annual review of cell and developmental biology 23 (2007) 519.

[14] M. Babst, A protein's final ESCRT, Traffic 6(1) (2005) 2-9. 
[15] L. Christ, C. Raiborg, E.M. Wenzel, C. Campsteijn, H. Stenmark, Cellular functions and molecular mechanisms of the ESCRT membrane-scission machinery, Trends in biochemical sciences 42(1) (2017) 42-56.

[16] S.K. Mageswaran, N.K. Johnson, G. Odorizzi, M. Babst, Constitutively active ESCRT-II suppresses the MVB-sorting phenotype of ESCRT-0 and ESCRT-I mutants, Molecular biology of the cell 26(3) (2015) 554-568.

[17] T. Wollert, J.H. Hurley, Molecular mechanism of multivesicular body biogenesis by ESCRT complexes, Nature 464(7290) (2010) 864.

[18] E. Boura, B. Różycki, H.S. Chung, D.Z. Herrick, B. Canagarajah, D.S. Cafiso, W.A. Eaton, G. Hummer, J.H. Hurley, Solution structure of the ESCRT-I and-II supercomplex: implications for membrane budding and scission, Structure 20(5) (2012) 874-886.

[19] O. Schmidt, D. Teis, The ESCRT machinery, Current Biology 22(4) (2012) R116-R120.

[20] N. Wolters, A. Amerik, The N-terminal domains determine cellular localization and functions of the Doa4 and Ubp5 deubiquitinating enzymes, Biochemical and biophysical research communications 467(3) (2015) 570-576.

[21] N. Johnson, M. West, G. Odorizzi, Regulation of yeast ESCRT-III membrane scission activity by the Doa4 ubiquitin hydrolase, Molecular biology of the cell 28(5) (2017) 661-672.

[22] N. Luhtala, G. Odorizzi, Bro1 coordinates deubiquitination in the multivesicular body pathway by recruiting Doa4 to endosomes, The Journal of cell biology 166(5) (2004) 717-729.

[23] A. Shestakova, Functional and biochemical studies of the Vps4 ATPase in Saccharomyces cerevisiae, The University of Utah2011.

[24] T. Yoshimori, F. Yamagata, A. Yamamoto, N. Mizushima, Y. Kabeya, A. Nara, I. Miwako, M. Ohashi, M. Ohsumi, Y. Ohsumi, The mouse SKD1, a homologue of yeast Vps4p, is required for normal endosomal trafficking and morphology in mammalian cells, Molecular Biology of the Cell 11(2) (2000) 747-763.

[25] W.M. Henne, N.J. Buchkovich, S.D. Emr, The ESCRT pathway, Developmental cell 21(1) (2011) 77-91.

[26] I. Azmi, B. Davies, C. Dimaano, J. Payne, D. Eckert, M. Babst, D.J. Katzmann, Recycling of ESCRTs by the AAA-ATPase Vps4 is regulated by a conserved VSL region in Vta1, The Journal of cell biology 172(5) (2006) 705-717.

[27] J.M. Lottridge, A.R. Flannery, J.L. Vincelli, T.H. Stevens, Vta1p and Vps46p regulate the membrane association and ATPase activity of Vps4p at the yeast multivesicular body, Proceedings of the National Academy of Sciences 103(16) (2006) 6202-6207.

[28] M. Su, E.Z. Guo, X. Ding, Y. Li, J.T. Tarrasch, C.L. Brooks, Z. Xu, G. Skiniotis, Mechanism of Vps4 hexamer function revealed by cryo-EM, Science Advances 3(4) (2017) e1700325.

[29] P.R. Vajjhala, J.S. Wong, H.Y. To, A.L. Munn, The $\beta$ domain is required for Vps4p oligomerization into a functionally active ATPase, The FEBS journal 273(11) (2006) 23572373.

[30] F. Reggiori, D.J. Klionsky, Autophagic processes in yeast: mechanism, machinery and regulation, Genetics 194(2) (2013) 341-361.

[31] J.H. Rothman, T.H. Stevens, Protein sorting in yeast: mutants defective in vacuole biogenesis mislocalize vacuolar proteins into the late secretory pathway, Cell 47(6) (1986) 1041-1051.

[32] J.S. Robinson, D.J. Klionsky, L.M. Banta, S.D. Emr, Protein sorting in Saccharomyces cerevisiae: isolation of mutants defective in the delivery and processing of multiple vacuolar hydrolases, Molecular and cellular biology 8(11) (1988) 4936-4948.

[33] J.D. Shaw, K.B. Cummings, G. Huyer, S. Michaelis, B. Wendland, Yeast as a model system for studying endocytosis, Experimental cell research 271(1) (2001) 1-9. 
[34] C.K. Raymond, I. Howald-Stevenson, C. Vater, T. Stevens, Morphological classification of the yeast vacuolar protein sorting mutants: evidence for a prevacuolar compartment in class E vps mutants, Molecular biology of the cell 3(12) (1992) 1389-1402.

[35] E.M. Coonrod, T.H. Stevens, The yeast vps class E mutants: the beginning of the molecular genetic analysis of multivesicular body biogenesis, Molecular biology of the cell 21(23) (2010) 4057-4060.

[36] K. Bowers, T.H. Stevens, Protein transport from the late Golgi to the vacuole in the yeast Saccharomyces cerevisiae, Biochimica et Biophysica Acta (BBA)-Molecular Cell Research 1744(3) (2005) 438-454.

[37] F. Reggiori, H.R. Pelham, Sorting of proteins into multivesicular bodies: ubiquitindependent and-independent targeting, The EMBO journal 20(18) (2001) 5176-5186.

[38] S. Saksena, J. Sun, T. Chu, S.D. Emr, ESCRTing proteins in the endocytic pathway, Trends in biochemical sciences 32(12) (2007) 561-573.

[39] M. Babst, D.J. Katzmann, E.J. Estepa-Sabal, T. Meerloo, S.D. Emr, Escrt-III: an endosome-associated heterooligomeric protein complex required for mvb sorting, Developmental cell 3(2) (2002) 271-282.

[40] M. Babst, D.J. Katzmann, W.B. Snyder, B. Wendland, S.D. Emr, Endosome-associated complex, ESCRT-II, recruits transport machinery for protein sorting at the multivesicular body, Developmental cell 3(2) (2002) 283-289.

[41] N.K. Johnson, Regulation of the ESCRT-III Membrane Scission Machinery in Saccharomyces Cerevisiae. Molecular, Cellular, and Developmental Biology Graduate Theses \& Dissertations. (2016) 46. https://scholar.colorado.edu/mcdb_gradetds/46.

[42] B.E. Mierzwa, N. Chiaruttini, L. Redondo-Morata, J.M. von Filseck, J. König, J. Larios, I. Poser, T. Müller-Reichert, S. Scheuring, A. Roux, Dynamic subunit turnover in ESCRT-III assemblies is regulated by Vps4 to mediate membrane remodelling during cytokinesis, Nature cell biology 19(7) (2017) 787.

[43] M.A.Y. Adell, S.M. Migliano, S. Upadhyayula, Y.S. Bykov, S. Sprenger, M. Pakdel, G.F. Vogel, G. Jih, W. Skillern, R. Behrouzi, M. Babst, O. Schmidt, M.W. Hess, J.A.G. Briggs, T. Kirchhausen, D. Teis, Recruitment dynamics of ESCRT-III and Vps4 to endosomes and implications for reverse membrane budding, Elife 6 (2017), e31652.

[44] W.M. Henne, H. Stenmark, S.D. Emr, Molecular mechanisms of the membrane sculpting ESCRT pathway, Cold Spring Harbor Perspectives in Biology 5(9) (2013) a016766.

[45] M. Bajorek, H.L. Schubert, J. McCullough, C. Langelier, D.M. Eckert, W.-M.B. Stubblefield, N.T. Uter, D.G. Myszka, C.P. Hill, W.I. Sundquist, Structural basis for ESCRTIII protein autoinhibition, Nature structural \& molecular biology 16(7) (2009) 754-762.

[46] U.K. von Schwedler, M. Stuchell, B. Müller, D.M. Ward, H.-Y. Chung, E. Morita, H.E. Wang, T. Davis, G.-P. He, D.M. Cimbora, The protein network of HIV budding, Cell 114(6) (2003) 701-713.

[47] J. McCullough, L.A. Colf, W.I. Sundquist, Membrane fission reactions of the mammalian ESCRT pathway, Annual review of biochemistry 82 (2013) 663-692.

[48] N. Foot, T. Henshall, S. Kumar, Ubiquitination and the regulation of membrane proteins, Physiological reviews 97(1) (2016) 253-281.

[49] D. Mukhopadhyay, H. Riezman, Proteasome-independent functions of ubiquitin in endocytosis and signaling, Science 315(5809) (2007) 201-205.

[50] R.C. Piper, I. Dikic, G.L. Lukacs, Ubiquitin-dependent sorting in endocytosis, Cold Spring Harbor Perspectives in Biology 6(1) (2014) a016808.

[51] A. Shestakova, A. Hanono, S. Drosner, M. Curtiss, B.A. Davies, D.J. Katzmann, M. Babst, Assembly of the AAA ATPase Vps4 on ESCRT-III, Molecular biology of the cell 21(6) (2010) 1059-1071. 
[52] L. Hicke, R. Dunn, Regulation of membrane protein transport by ubiquitin and ubiquitinbinding proteins, Annual review of cell and developmental biology 19(1) (2003) 141-172.

[53] J.H. Hurley, The ESCRT complexes, Critical reviews in biochemistry and molecular biology 45(6) (2010) 463-487.

[54] J. Huotari, A. Helenius, Endosome maturation, The EMBO journal 30(17) (2011) 34813500 .

[55] D.P. Nickerson, M.R. Russell, G. Odorizzi, A concentric circle model of multivesicular body cargo sorting, EMBO reports 8(7) (2007) 644-650.

[56] M. Tkach, J. Kowal, C. Théry, Why the need and how to approach the functional diversity of extracellular vesicles, Phil. Trans. R. Soc. B 373(1737) (2018) 20160479.

[57] J. Kowal, M. Tkach, C. Théry, Biogenesis and secretion of exosomes, Current opinion in cell biology 29 (2014) 116-125.

[58] T. Slagsvold, K. Pattni, L. Malerød, H. Stenmark, Endosomal and non-endosomal functions of ESCRT proteins, Trends in cell biology 16(6) (2006) 317-326.

[59] M.A.Y. Adell, D. Teis, Assembly and disassembly of the ESCRT-III membrane scission complex (vol 585, pg 3191, 2011), Febs Letters 586(2) (2012) 204-204.

[60] D.L. Oliveira, J. Rizzo, L.S. Joffe, R. Godinho, M.L. Rodrigues, Where do they come from and where do they go: candidates for regulating extracellular vesicle formation in fungi, International journal of molecular sciences 14(5) (2013) 9581-9603.

[61] J. Horák, The role of ubiquitin in down-regulation and intracellular sorting of membrane proteins: insights from yeast, Biochimica et Biophysica Acta (BBA)-Biomembranes 1614(2) (2003) 139-155.

[62] C. Raiborg, H. Stenmark, The ESCRT machinery in endosomal sorting of ubiquitylated membrane proteins, Nature 458(7237) (2009) 445.

[63] A.L. Munn, H. Riezman, Endocytosis is required for the growth of vacuolar H (+)ATPase-defective yeast: identification of six new END genes, The Journal of Cell Biology 127(2) (1994) 373-386.

[64] K. Haglund, I. Dikic, The role of ubiquitylation in receptor endocytosis and endosomal sorting, Journal of cell science 125(2) (2012) 265-275.

[65] D.J. Katzmann, G. Odorizzi, S.D. Emr, Receptor downregulation and multivesicular-body sorting, Nature reviews Molecular cell biology 3(12) (2002) 893-905.

[66] N. Pashkova, L. Gakhar, S.C. Winistorfer, A.B. Sunshine, M. Rich, M.J. Dunham, L. Yu, R.C. Piper, The yeast Alix homolog Brol functions as a ubiquitin receptor for protein sorting into multivesicular endosomes, Developmental cell 25(5) (2013) 520-533.

[67] C.L. Stoten, J.G. Carlton, ESCRT-dependent control of membrane remodelling during cell division, Seminars in cell \& developmental biology, Elsevier, 2017.

[68] J.G. Carlton, J. Martin-Serrano, Parallels between cytokinesis and retroviral budding: a role for the ESCRT machinery, Science 316(5833) (2007) 1908-1912.

[69] J.H. Hurley, P.I. Hanson, Membrane budding and scission by the ESCRT machinery: it's all in the neck, Nature reviews Molecular cell biology 11(8) (2010) 556.

[70] N. Monroe, H. Han, M.D. Gonciarz, D.M. Eckert, M.A. Karren, F.G. Whitby, W.I. Sundquist, C.P. Hill, The oligomeric state of the active Vps4 AAA ATPase, Journal of molecular biology 426(3) (2014) 510-525.

[71] P.R. Vajjhala, E. Catchpoole, C.H. Nguyen, C. Kistler, A.L. Munn, Vps4 regulates a subset of protein interactions at the multivesicular endosome, Febs Journal 274(8) (2007) 18941907.

[72] B. Yang, G. Stjepanovic, Q. Shen, A. Martin, J.H. Hurley, Vps4 disassembles an ESCRTIII filament by global unfolding and processive translocation, Nature structural \& molecular biology 22(6) (2015) 492-498. 
[73] H. Teo, O. Perisic, B. González, R.L. Williams, ESCRT-II, an endosome-associated complex required for protein sorting: crystal structure and interactions with ESCRT-III and membranes, Developmental cell 7(4) (2004) 559-569.

[74] D.J. Katzmann, C.J. Stefan, M. Babst, S.D. Emr, Vps 27 recruits ESCRT machinery to endosomes during MVB sorting, J Cell Biol 162(3) (2003) 413-423.

[75] S. Tang, N.J. Buchkovich, W.M. Henne, S. Banjade, Y.J. Kim, S.D. Emr, ESCRT-III activation by parallel action of ESCRT-I/II and ESCRT-0/Bro1 during MVB biogenesis, Elife 5 (2016) e15507.

[76] C.P. Hill, M. Babst, Structure and function of the membrane deformation AAA ATPase Vps4, Biochimica et Biophysica Acta (BBA)-Molecular Cell Research 1823(1) (2012) 172181.

[77] B.A. Davies, I.F. Azmi, J. Payne, A. Shestakova, B.F. Horazdovsky, M. Babst, D.J. Katzmann, Coordination of substrate binding and ATP hydrolysis in Vps4-mediated ESCRTIII disassembly, Molecular biology of the cell 21(19) (2010) 3396-3408.

[78] S.B. Shields, R.C. Piper, How ubiquitin functions with ESCRTs, Traffic 12(10) (2011) 1306-1317.

[79] H. Han, N. Monroe, W.I. Sundquist, P.S. Shen, C.P. Hill, The AAA ATPase Vps4 binds ESCRT-III substrates through a repeating array of dipeptide-binding pockets, eLife 6 (2017) e31324.

[80] H. Han, N. Monroe, J. Votteler, B. Shakya, W.I. Sundquist, C.P. Hill, Binding of substrates to the central pore of the Vps4 ATPase is autoinhibited by the microtubule interacting and trafficking (MIT) domain and activated by MIT interacting motifs (MIMs), Journal of Biological Chemistry (2015) jbc. M115. 642355.

[81] E. Conibear, An ESCRT into the endosome, Molecular cell 10(2) (2002) 215-216.

[82] C. Raiborg, T.E. Rusten, H. Stenmark, Protein sorting into multivesicular endosomes, Current opinion in cell biology 15(4) (2003) 446-455.

[83] P.S. Bilodeau, S.C. Winistorfer, W.R. Kearney, A.D. Robertson, R.C. Piper, Vps27-Hse1 and ESCRT-I complexes cooperate to increase efficiency of sorting ubiquitinated proteins at the endosome, J Cell Biol 163(2) (2003) 237-243.

[84] M.S. Kostelansky, C. Schluter, Y.Y.C. Tam, S. Lee, R. Ghirlando, B. Beach, E. Conibear, J.H. Hurley, Molecular architecture and functional model of the complete yeast ESCRT-I heterotetramer, Cell 129(3) (2007) 485-498.

[85] E. Conibear, Converging views of endocytosis in yeast and mammals, Current opinion in cell biology 22(4) (2010) 513-518.

[86] J.A. MacGurn, P.-C. Hsu, S.D. Emr, Ubiquitin and membrane protein turnover: from cradle to grave, Annual review of biochemistry 81 (2012) 231-259.

[87] S. Polo, Signaling-mediated control of ubiquitin ligases in endocytosis, BMC biology 10(1) (2012) 25.

[88] J. Broniarczyk, M. Bergant, A. Goździcka-Józefiak, L. Banks, Human papillomavirus infection requires the TSG101 component of the ESCRT machinery, Virology 460 (2014) 8390.

[89] J.T. White, D. Toptygin, R. Cohen, N. Murphy, V.J. Hilser, Structural Stability of the coiled-coil domain of Tumor Susceptibility Gene (TSG)-101, Biochemistry 56(35) (2017) 4646-4655.

[90] M. Babst, G. Odorizzi, E.J. Estepa, S.D. Emr, Mammalian tumor susceptibility gene 101 (TSG101) and the yeast homologue, Vps23p, both function in late endosomal trafficking, Traffic 1(3) (2000) 248-258.

[91] M.A. Wemmer, Regulation of ESCRT-III assembly and membrane scission activity in the budding yeast Saccharomyces cerevisiae, University of Colorado at Boulder, 2011. 
[92] Y. Li, T. Kane, C. Tipper, P. Spatrick, D.D. Jenness, Yeast mutants affecting possible quality control of plasma membrane proteins, Molecular and Cellular Biology 19(5) (1999) 3588-3599.

[93] N. Bishop, P. Woodman, TSG101/mammalian VPS23 and mammalian VPS28 interact directly and are recruited to VPS4-induced endosomes, Journal of Biological Chemistry 276(15) (2001) 11735-11742.

[94] N. Tanaka, M. Kyuuma, K. Sugamura, Endosomal sorting complex required for transport proteins in cancer pathogenesis, vesicular transport, and non-endosomal functions, Cancer science 99(7) (2008) 1293-1303.

[95] A.N. Martins, A.A. Waheed, S.D. Ablan, W. Huang, A. Newton, C.J. Petropoulos, R.D. Brindeiro, E.O. Freed, Elucidation of the molecular mechanism driving duplication of the HIV1 PTAP late domain, Journal of virology 90(2) (2016) 768-779.

[96] R.D. Fisher, H.-Y. Chung, Q. Zhai, H. Robinson, W.I. Sundquist, C.P. Hill, Structural and biochemical studies of ALIX/AIP1 and its role in retrovirus budding, Cell 128(5) (2007) 841852.

[97] C.A. Carter, Tsg101: HIV-1's ticket to ride, Trends in microbiology 10(5) (2002) 203-205. [98] L.S. Ehrlich, C.A. Carter, HIV Assembly and Budding: $\mathrm{Ca}^{2}$, Molecular biology international 2012 (2012) Article ID 851670, 12 pages, DOI: 10.1155/2012/851670.

[99] L.S. Silvestri, G. Ruthel, G. Kallstrom, K.L. Warfield, D.L. Swenson, T. Nelle, P.L. Iversen, S. Bavari, M.J. Aman, Involvement of vacuolar protein sorting pathway in Ebola virus release independent of TSG101 interaction, Journal of Infectious Diseases 196(Supplement 2) (2007) S264-S270.

[100] D. Teis, S. Saksena, B.L. Judson, S.D. Emr, ESCRT-II coordinates the assembly of ESCRT-III filaments for cargo sorting and multivesicular body vesicle formation, The EMBO journal 29(5) (2010) 871-883.

[101] E.B. Frankel, A. Audhya, ESCRT-dependent cargo sorting at multivesicular endosomes, Seminars in Cell \& Developmental Biology 74 (2018) 4-10.

[102] T. Kirchhausen, D. Owen, S.C. Harrison, Molecular structure, function, and dynamics of clathrin-mediated membrane traffic, Cold Spring Harbor perspectives in biology 6(5) (2014) $\mathrm{a} 016725$.

[103] D. Teis, S. Saksena, S.D. Emr, Ordered assembly of the ESCRT-III complex on endosomes is required to sequester cargo during MVB formation, Developmental cell 15(4) (2008) 578-589.

[104] S. Sun, L. Li, F. Yang, X. Wang, F. Fan, M. Yang, C. Chen, X. Li, H.-W. Wang, S.-F. Sui, Cryo-EM structures of the ATP-bound Vps4 E233Q hexamer and its complex with Vta1 at near-atomic resolution, Nature communications 8 (2017) 16064.

[105] N. Monroe, H. Han, P.S. Shen, W.I. Sundquist, C.P. Hill, Structural basis of protein translocation by the Vps4-Vta1 AAA ATPase, Elife 6 (2017) e24487.

[106] M.J. Landsberg, P.R. Vajjhala, R. Rothnagel, A.L. Munn, B. Hankamer, Threedimensional structure of AAA ATPase Vps4: advancing structural insights into the mechanisms of endosomal sorting and enveloped virus budding, Structure 17(3) (2009) 427 437.

[107] Z. Yu, M.D. Gonciarz, W.I. Sundquist, C.P. Hill, G.J. Jensen, Cryo-EM structure of dodecameric Vps4p and its 2: 1 complex with Vta1p, Journal of molecular biology 377(2) (2008) 364-377.

[108] S.C. Yeo, L. Xu, J. Ren, V.J. Boulton, M.D. Wagle, C. Liu, G. Ren, P. Wong, R. Zahn, P. Sasajala, Vps20p and Vta1p interact with Vps4p and function in multivesicular body sorting and endosomal transport in Saccharomyces cerevisiae, J Cell Sci 116(19) (2003) 3957-3970. 
[109] G. Odorizzi, D.J. Katzmann, M. Babst, A. Audhya, S.D. Emr, Bro1 is an endosomeassociated protein that functions in the MVB pathway in Saccharomyces cerevisiae, Journal of cell science 116(10) (2003) 1893-1903.

[110] C. Caillat, P. Macheboeuf, Y.F. Wu, A.A. McCarthy, E. Boeri-Erba, G. Effantin, H.G. Gottlinger, W. Weissenhorn, P. Renesto, Asymmetric ring structure of Vps4 required for ESCRT-III disassembly, Nature Communications 6 (2015) 8781.

[111] N. Monroe, C.P. Hill, Meiotic clade AAA ATPases: protein polymer disassembly machines, Journal of molecular biology 428(9) (2016) 1897-1911.

[112] A. Scott, J. Gaspar, M.D. Stuchell-Brereton, S.L. Alam, J.J. Skalicky, W.I. Sundquist, Structure and ESCRT-III protein interactions of the MIT domain of human VPS4A, Proceedings of the National Academy of Sciences of the United States of America 102(39) (2005) 13813-13818.

[113] M. Babst, B. Wendland, E.J. Estepa, S.D. Emr, The Vps4p AAA ATPase regulates membrane association of a Vps protein complex required for normal endosome function, The EMBO journal 17(11) (1998) 2982-2993.

[114] C.J. Vild, Z. Xu, Vfal binds to the N-terminal microtubule-interacting and trafficking (MIT) domain of Vps4 and stimulates its ATPase activity, Journal of Biological Chemistry 289(15) (2014) 10378-10386.

[115] J.H. Hurley, D. Yang, MIT domainia, Developmental cell 14(1) (2008) 6-8.

[116] M.D. Stuchell-Brereton, J.J. Skalicky, C. Kieffer, M.A. Karren, S. Ghaffarian, W.I. Sundquist, ESCRT-III recognition by vps4 ATPases, Nature 449(7163) (2007) 740-744.

[117] A. Shestakova, M. Curtiss, B.A. Davies, D.J. Katzmann, M. Babst, The linker region plays a regulatory role in assembly and activity of the Vps4 AAA ATPase, Journal of Biological Chemistry 288(37) (2013) 26810-26819.

[118] J. Xiao, H. Xia, K. Yoshino-Koh, J. Zhou, Z. Xu, Structural characterization of the ATPase reaction cycle of endosomal AAA protein Vps4, Journal of molecular biology 374(3) (2007) 655-670.

[119] J. Xiao, H. Xia, J. Zhou, I.F. Azmi, B.A. Davies, D.J. Katzmann, Z. Xu, Structural basis of Vtal function in the multivesicular body sorting pathway, Developmental cell 14(1) (2008) 37-49.

[120] D. Yang, J.H. Hurley, Structural role of the Vps4-Vta1 interface in ESCRT-III recycling, Structure 18(8) (2010) 976-984.

[121] B.A. Davies, A.P. Norgan, J.A. Payne, M.E. Schulz, M.D. Nichols, J.A. Tan, Z. Xu, D.J. Katzmann, Vps4 stimulatory element of the cofactor Vtal contacts the ATPase Vps $4 \alpha 7$ and $\alpha 9$ to stimulate ATP hydrolysis, Journal of Biological Chemistry 289(41) (2014) 28707-28718. [122] I.F. Azmi, B.A. Davies, J. Xiao, M. Babst, Z. Xu, D.J. Katzmann, ESCRT-III family members stimulate Vps4 ATPase activity directly or via Vta1, Developmental cell 14(1) (2008) 50-61.

[123] M.A.Y. Adell, G.F. Vogel, M. Pakdel, M. Müller, H. Lindner, M.W. Hess, D. Teis, Coordinated binding of Vps4 to ESCRT-III drives membrane neck constriction during MVB vesicle formation, J Cell Biol 205(1) (2014) 33-49.

[124] M. Zhadina, P.D. Bieniasz, Functional interchangeability of late domains, late domain cofactors and ubiquitin in viral budding, PLoS Pathog 6(10) (2010) e1001153.

[125] J. Martin-Serrano, S.W. Eastman, W. Chung, P.D. Bieniasz, HECT ubiquitin ligases link viral and cellular PPXY motifs to the vacuolar protein-sorting pathway, The Journal of cell biology 168(1) (2005) 89-101.

[126] B.J. Chen, R.A. Lamb, Mechanisms for enveloped virus budding: can some viruses do without an ESCRT?, Virology 372(2) (2008) 221-232.

[127] B.K. Ganser-Pornillos, M. Yeager, O. Pornillos, Assembly and architecture of HIV, Viral molecular machines, Springer2012, pp. 441-465. 
[128] W.I. Sundquist, H.-G. Kräusslich, HIV-1 assembly, budding, and maturation, Cold Spring Harbor perspectives in medicine 2(7) (2012) a006924.

[129] B. Meng, A. Lever, Wrapping up the bad news: HIV assembly and release, Retrovirology 10(5) (2013) 4690-10.

[130] J.B. Ames, T. Tanaka, L. Stryer, M. Ikura, Portrait of a myristoyl switch protein, Current Opinion in Structural Biology 6(4) (1996) 432-438.

[131] E. Barklis, J. McDermott, S. Wilkens, E. Schabtach, M.F. Schmid, S. Fuller, S. Karanjia, Z. Love, R. Jones, Y.J. Rui, X.M. Zhao, D. Thompson, Structural analysis of membrane-bound retrovirus capsid proteins, Embo Journal 16(6) (1997) 1199-1213.

[132] A.D. Frankel, J.A.T. Young, HIV-1: Fifteen proteins and an RNA, Annual Review of Biochemistry 67 (1998) 1-25.

[133] C. Momany, L.C. Kovari, A.J. Prongay, W. Keller, R.K. Gitti, B.M. Lee, A.E. Gorbalenya, L. Tong, J. McClure, L.S. Ehrlich, M.F. Summers, C. Carter, M.G. Rossmann, Crystal structure of dimeric HIV-1 capsid protein, Nature Structural Biology 3(9) (1996) 763770 .

[134] J.S. Saad, J. Miller, J. Tai, A. Kim, R.H. Ghanam, M.F. Summers, Structural basis for targeting HIV-1 Gag proteins to the plasma membrane for virus assembly, Proceedings of the National Academy of Sciences 103(30) (2006) 11364-11369.

[135] D. Gheysen, E. Jacobs, F. de Foresta, C. Thiriart, M. Francotte, D. Thines, M. De Wilde, Assembly and release of HIV-1 precursor Pr55 gag virus-like particles from recombinant baculovirus-infected insect cells, Cell 59(1) (1989) 103-112.

[136] Z. Rao, A.S. Belyaev, E. Fry, P. Roy, I.M. Jones, D.I. Stuart, Crystal structure of SIV matrix antigen and implications for virus assembly, Nature 378(6558) (1995) 743-747.

[137] W. Zhou, L. Parent, J. Wills, M. Resh, Identification of a membrane-binding domain within the amino-terminal region of human immunodeficiency virus type 1 Gag protein which interacts with acidic phospholipids, Journal of virology 68(4) (1994) 2556-2569.

[138] M.D. Resh, A myristoyl switch regulates membrane binding of HIV-1 Gag, Proceedings of the National Academy of Sciences 101(2) (2004) 417-418.

[139] S. Debaisieux, F. Rayne, H. Yezid, B. Beaumelle, The Ins and Outs of HIV-1 Tat, Traffic 13(3) (2012) 355-363.

[140] A. Ono, S.D. Ablan, S.J. Lockett, K. Nagashima, E.O. Freed, Phosphatidylinositol $(4,5)$ bisphosphate regulates HIV-1 Gag targeting to the plasma membrane, Proceedings of the National Academy of Sciences of the United States of America 101(41) (2004) 14889-14894. [141] Y.J. Im, L. Kuo, X. Ren, P.V. Burgos, X.Z. Zhao, F. Liu, T.R. Burke, J.S. Bonifacino, E.O. Freed, J.H. Hurley, Crystallographic and functional analysis of the ESCRT-I/HIV-1 Gag PTAP interaction, Structure 18(11) (2010) 1536-1547.

[142] E.J. Arts, D.J. Hazuda, HIV-1 antiretroviral drug therapy, Cold Spring Harbor perspectives in medicine (2012) a007161.

[143] O. Pornillos, S.L. Alam, D.R. Davis, W.I. Sundquist, Structure of the Tsg101 UEV domain in complex with the PTAP motif of the HIV-1 p6 protein, Nature Structural \& Molecular Biology 9(11) (2002) 812-817.

[144] C. Flexner, HIV drug development: the next 25 years, Nature Reviews Drug Discovery 6(12) (2007) 959.

[145] D.L. Swenson, K.L. Warfield, K. Kuehl, T. Larsen, M.C. Hevey, A. Schmaljohn, S. Bavari, M.J. Aman, Generation of Marburg virus-like particles by co-expression of glycoprotein and matrix protein, FEMS Immunology \& Medical Microbiology 40(1) (2004) 27-31.

[146] S.A. Valkenburg, N.H.L. Leung, M.B. Bull, L.M. Yan, A.P.Y. Li, L.L.M. Poon, B.J. Cowling, The Hurdles From Bench to Bedside in the Realization and Implementation of a Universal Influenza Vaccine, Frontiers in Immunology 9 (2018). 
[147] C. Yang, L. Ye, R.W. Compans, Protection against filovirus infection: virus-like particle vaccines, Expert review of vaccines 7(3) (2008) 333-344.

[148] T. Hoenen, L. Kolesnikova, S. Becker, Recent advances in filovirus-and arenavirus-like particles, Future Virology 2 (2007) 193-203, https://doi.org/10.2217/17460794.2.2.193.

[149] C. Hellmund, A.M.L. Lever, Coordination of Genomic RNA Packaging with Viral Assembly in HIV-1, Viruses-Basel 8(7) (2016), 192.

[150] D.S. Johnson, M. Bleck, S.M. Simon, Timing of ESCRT-III protein recruitment and membrane scission during HIV-1 assembly, eLlife 7 (2018) e36221.

[151] L. Kolesnikova, T. Strecker, E. Morita, F. Zielecki, E. Mittler, C. Crump, S. Becker, Vacuolar protein sorting pathway contributes to the release of Marburg virus, Journal of virology 83(5) (2009) 2327-2337.

[152] E.O. Freed, Viral late domains, Journal of Virology 76(10) (2002) 4679-4687.

[153] J.C. Akers, D. Gonda, R. Kim, B.S. Carter, C.C. Chen, Biogenesis of extracellular vesicles (EV): exosomes, microvesicles, retrovirus-like vesicles, and apoptotic bodies, Journal of neuro-oncology 113(1) (2013) 1-11.

[154] J.E. Garrus, U.K. von Schwedler, O.W. Pornillos, S.G. Morham, K.H. Zavitz, H.E. Wang, D.A. Wettstein, K.M. Stray, M. Côté, R.L. Rich, Tsg101 and the vacuolar protein sorting pathway are essential for HIV-1 budding, Cell 107(1) (2001) 55-65.

[155] A. Diaz, J. Zhang, A. Ollwerther, X. Wang, P. Ahlquist, Correction: Host ESCRT Proteins Are Required for Bromovirus RNA Replication Compartment Assembly and Function, PLoS Pathog 11(4) (2015) e1004845.

[156] G. Medina, Y. Zhang, Y. Tang, E. Gottwein, M.L. Vana, F. Bouamr, J. Leis, C.A. Carter, The functionally exchangeable L domains in RSV and HIV-1 Gag direct particle release through pathways linked by Tsg101, Traffic 6(10) (2005) 880-94.

[157] S. Urata, T. Noda, Y. Kawaoka, S. Morikawa, H. Yokosawa, J. Yasuda, Interaction of Tsg101 with Marburg virus VP40 depends on the PPPY motif, but not the PT/SAP motif as in the case of Ebola virus, and Tsg101 plays a critical role in the budding of Marburg virus-like particles induced by VP40, NP, and GP, J Virol 81(9) (2007) 4895-9.

[158] M. Babst, T.K. Sato, L.M. Banta, S.D. Emr, Endosomal transport function in yeast requires a novel AAA-type ATPase, Vps4p, The EMBO journal 16(8) (1997) 1820-1831.

[159] S. Scheuring, R.A. Röhricht, B. Schöning-Burkhardt, A. Beyer, S. Müller, H.F. Abts, K. Köhrer, Mammalian cells express two VPS4 proteins both of which are involved in intracellular protein trafficking, Journal of molecular biology 312(3) (2001) 469-480.

[160] E. Mittler, L. Kolesnikova, A. Herwig, O. Dolnik, S. Becker, Assembly of the Marburg virus envelope, Cellular microbiology 15(2) (2013) 270-284.

[161] K. Brauburger, A.J. Hume, E. Mühlberger, J. Olejnik, Forty-five years of Marburg virus research, Viruses 4(10) (2012) 1878-1927.

[162] L. Kolesnikova, B. Berghofer, S. Bamberg, S. Becker, Multivesicular bodies as a platform for formation of the Marburg virus envelope, J Virol 78(22) (2004) 12277-87. 


\title{
Figures
}

The regulation of ESCRTs and accessory proteins in MVB sorting and enveloped viral budding - an overview

\author{
Ishtiaq Ahmed*1, Zain Akram, Hafiz M. N. Iqbal ${ }^{2}$ and Alan L. Munn ${ }^{1}$
}
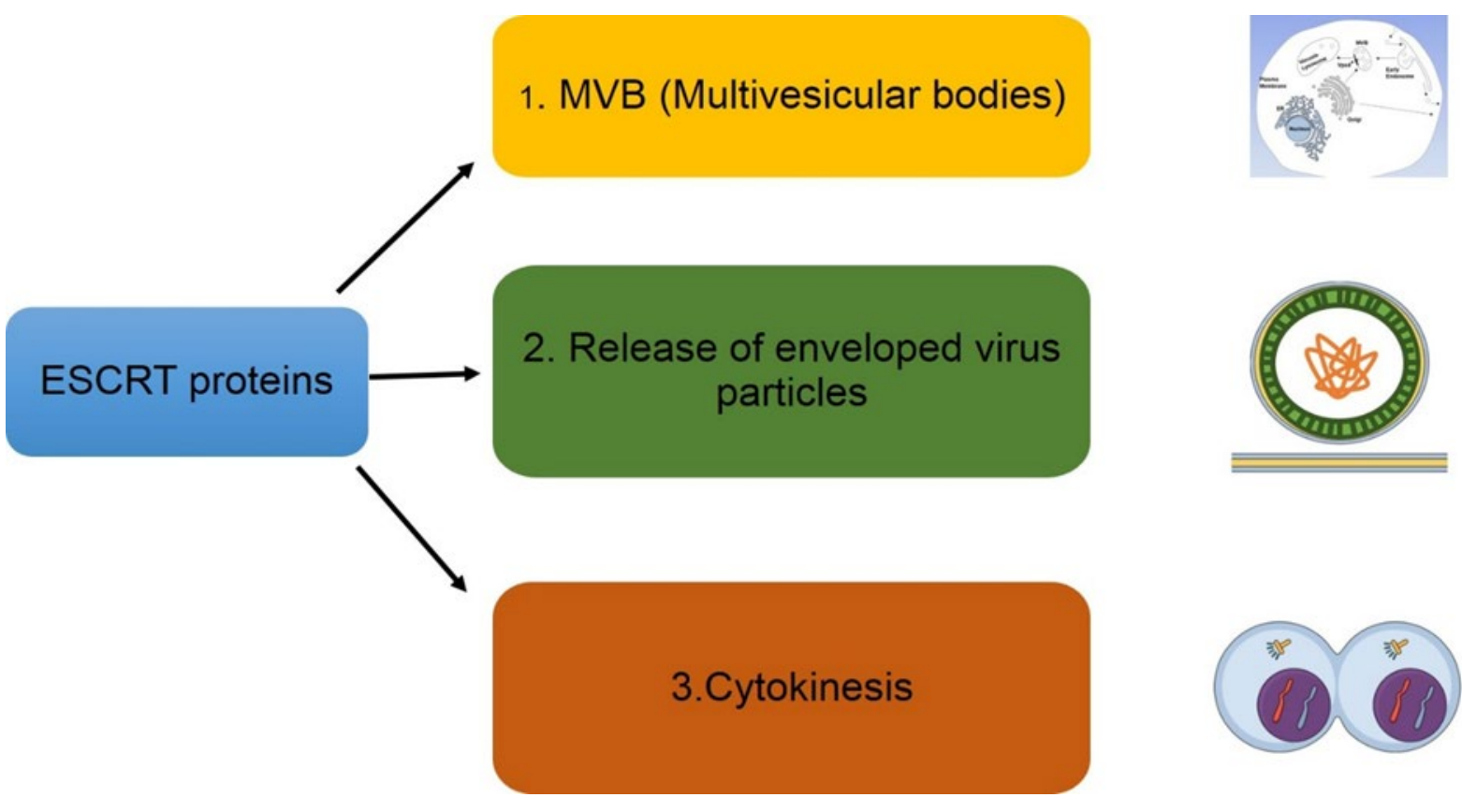

Graphical Abstract 


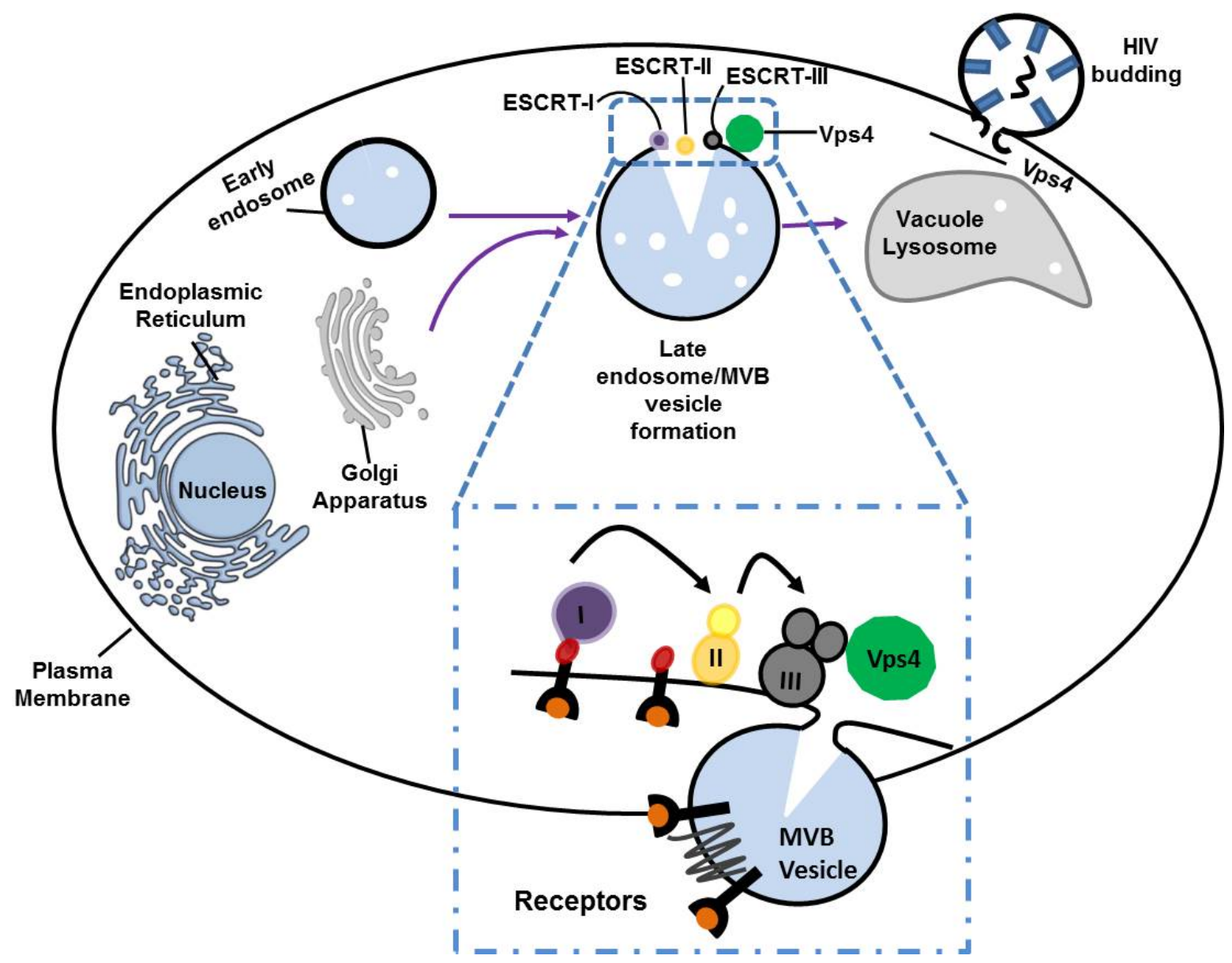

Figure 1. ESCRTs and Vps4p facilitates viral budding as well as the formation of MVB intralumenal vesicles. The transmembrane proteins are synthesised at the endoplasmic reticulum. Initially, transmembrane proteins are transported to the endosome or plasma membrane via the endoplasmic reticulum and the Golgi apparatus. Vps4p and ESCRT complexes function in protein sorting at the MVB (zoom view). The proteins and lipids of the vesicles are degraded upon the fusion of the MVB with the vacuole/lysosomes. The zoom view (dotted lines) illustrates the function of $\mathrm{Vps} 4 \mathrm{p}$, role of ubiquitin and ESCRT complexes in regulation of the MVB sorting of cargo membrane proteins into intraluminal vesicles. The model shows the covalent attachment of ubiquitin to a membrane-spanning cargo protein, the recognition of the ubiquitin tag on the membrane protein by ESCRT-I, the recruitment and assembly of first ESCRT-II and subsequently ESCRT-III, the concomitant membrane evagination and finally membrane scission to form a vesicle in the MVB lumen. The AAAATPase Vps4p facilitates the release of ESCRT complexes from the MVB after the completion of the vesicle budding process. In late-stage infection with HIV, the ESCRT complexes and Vps 4 are recruited to the plasma membrane where they enable the budding of the HIV particles. 

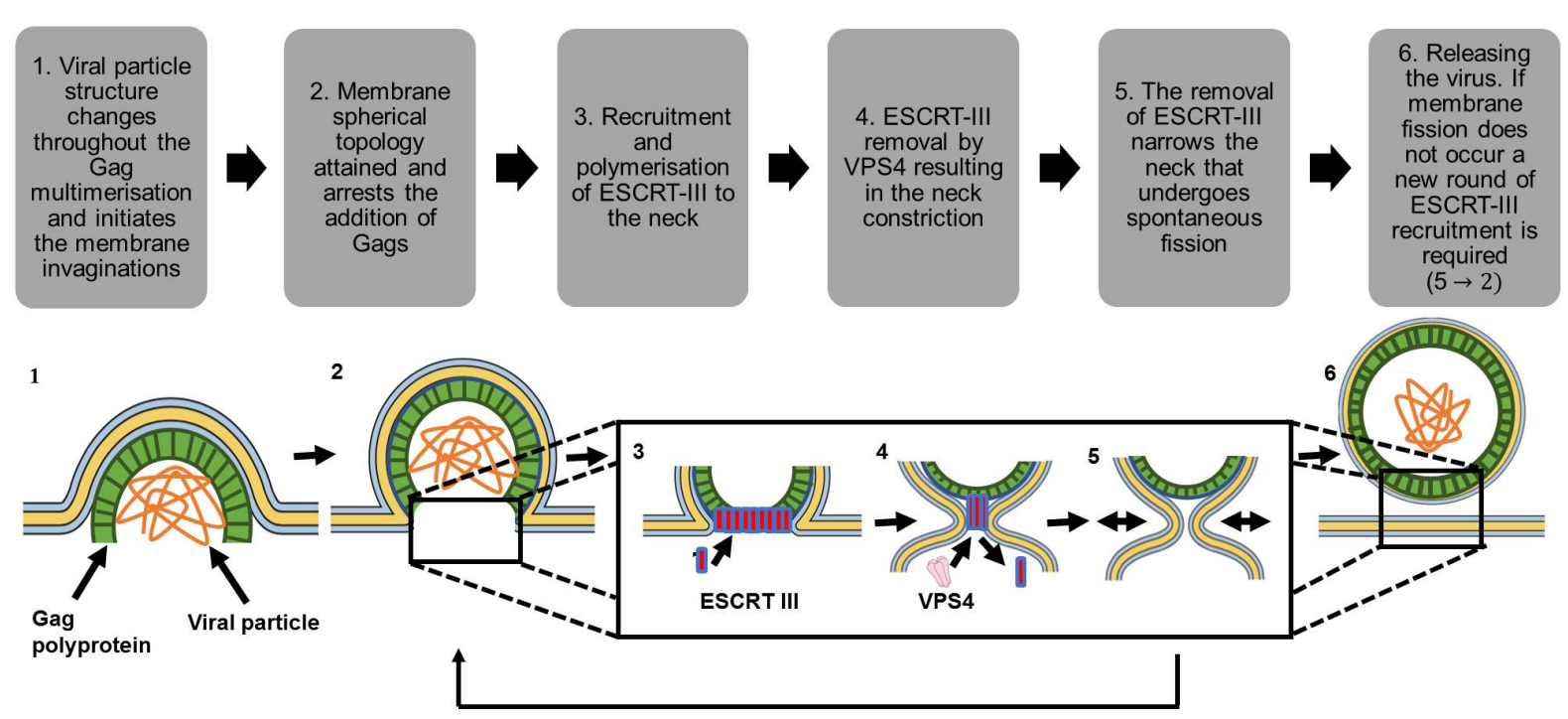

Figure 2: Model for how ESCRT-III mediates the scission of HIV from the cell plasma membrane. 


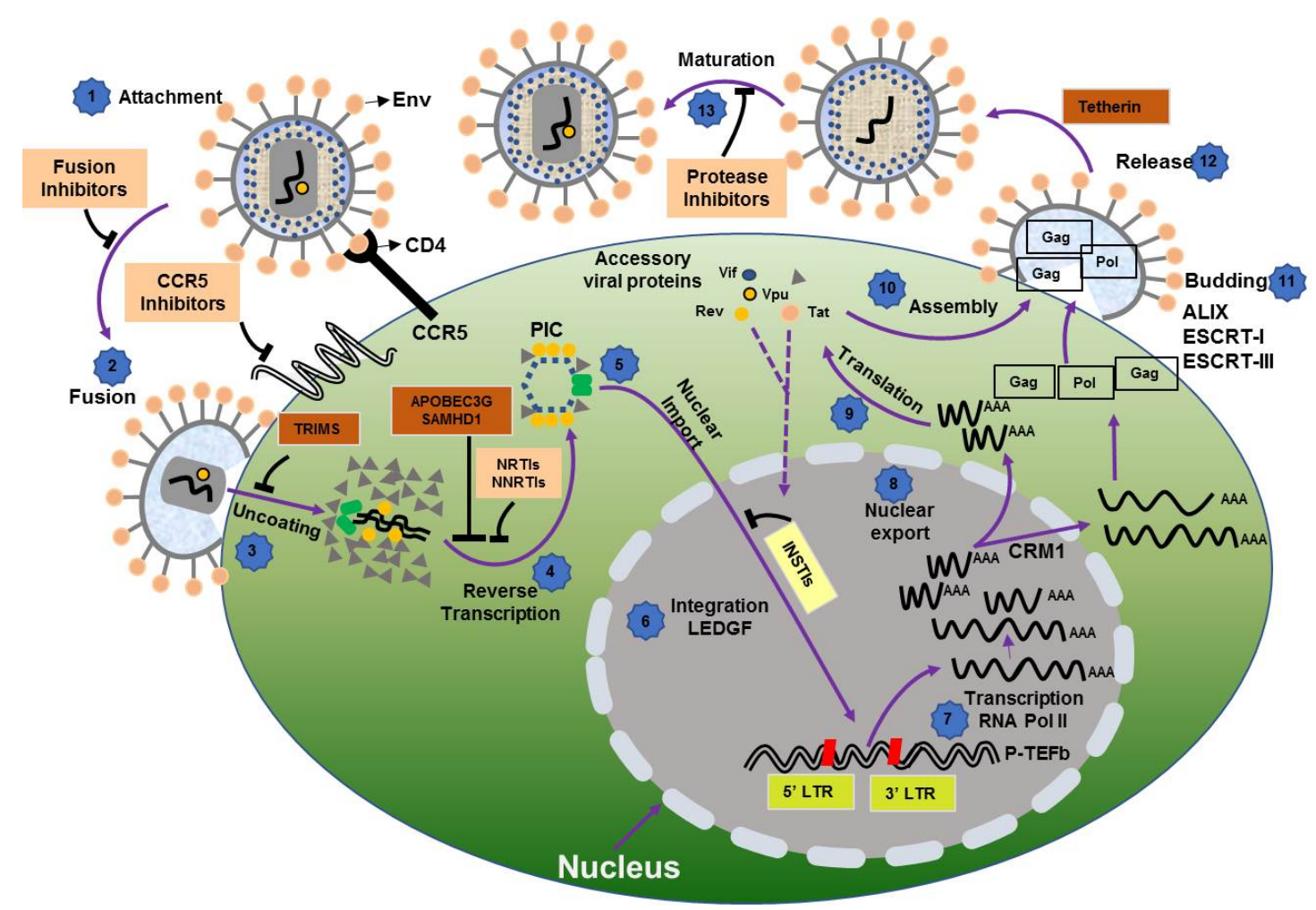

Figure 3. An overview of the HIV-1 life cycle. The infection begins when the envelope glycoprotein spikes recruit the receptor CD4 (e.g. a cell that expresses CD4 protein) and the membrane-spanning co-receptor CC-chemokine receptor 5 (CCR5), leading to fusion of the membranes (viral and cellular) and viral particle entry into the host cell. Partial uncoating of the core-shell enables reverse transcription, and this yields the pro-viral DNA. Pro-viral DNA is imported into the nucleus where integrase enzymes organise the formation of an integrated provirus. The host chromatin-binding protein LEDGF (lens epithelium-derived growth factor) supports the formation of the integrated pro-virus. Host RNA polymerase II (RNA Pol II) and $\mathrm{P}-\mathrm{TEFb}$ (positive transcription elongation factor $\mathrm{b}$ ) then mediate pro-viral transcription. This yields viral mRNAs of different sizes, the larger of which leave the nucleus. This export from the nucleus is energy-dependent and dependent on the host protein CRM1. The viral mRNAs serve as templates for protein production. Moreover, genome-length RNA and protein components are incorporated into viral particles. The ESCRT -I, -III and ALIX mediate the budding and release from the cell of viral particles, and release are soon followed by proteasemediated maturation to create an infectious viral particle.

Abbreviations: Nucleotide and Nucleoside Reverse Transcriptase Inhibitors (NRTIs); Integrase Strand Transfer Inhibitors (INSTIs); Non-Nucleoside Reverse Transcriptase 
Inhibitors (NNRTIs); Fusion Inhibitors (FIs); Protease Inhibitors (PIs); Long Terminal Repeat (LTR).

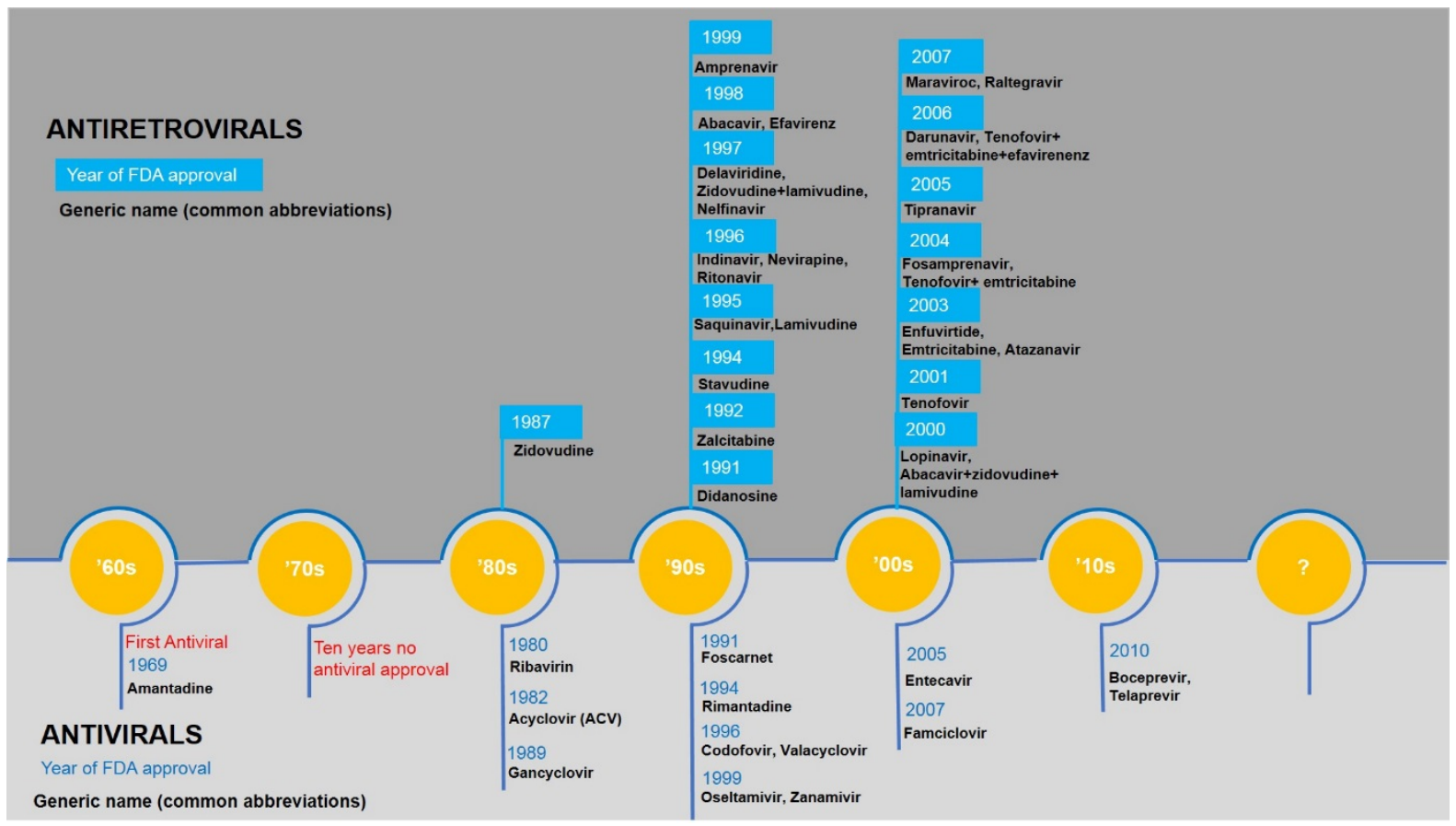

Figure 4. Trendline of FDA approval, current antiviral and antiretroviral drugs [142]. 